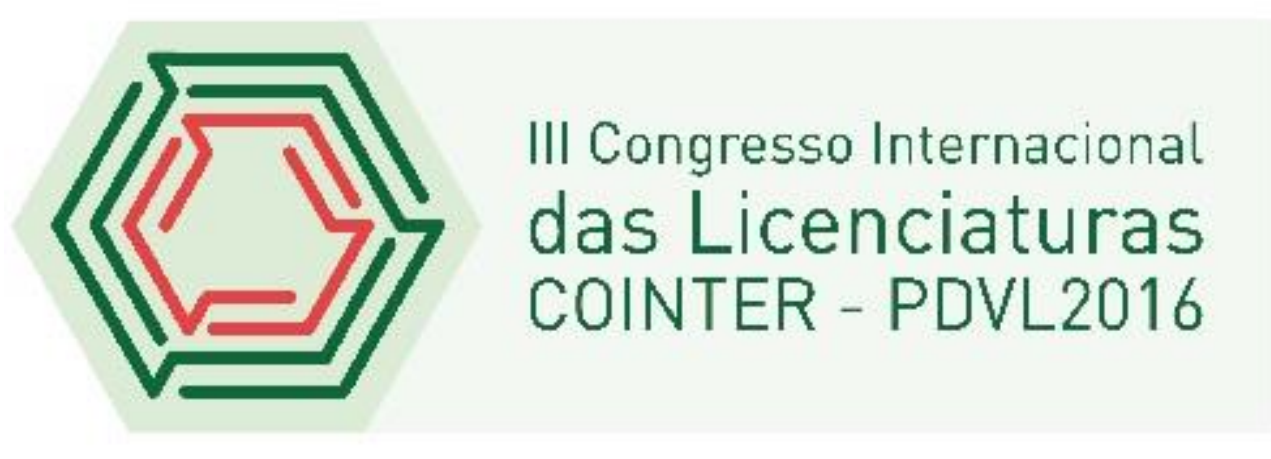

\title{
A PERSPECTIVA DOS ALUNOS DA REDE PÚBLICA QUANTO AO EXAME NACIONAL DO ENSINO MÉDIO COMO MEIO DE CHEGADA AO ENSINO SUPERIOR
}

Apresentação: Comunicação Oral

Edvania Pereira de Oliveira ${ }^{1}$; Leandro Araújo²; Daivyd Silva de Oliveira ${ }^{3}$ Ana Claudia da Silva Rodrigues $^{4}$

\begin{abstract}
Resumo
O Exame Nacional do Ensino Médio (Enem) foi criado em 1998 com o objetivo de avaliar o desempenho do estudante ao fim da educação básica, buscando contribuir para a melhoria da qualidade desse nível de escolaridade. INEP (2011). Desde sua criação o enem vem cada vez mais atraindo participantes e contribuindo para a melhoria da educação do nível médio. Devido a esta análise foi que desenvolvemos este trabalho, com a aplicação de questionário fechados destinados aos alunos do ensino médio do colégio agrícola Vidal de Negreiros e para os participantes do cursinho pró-enem que também é vinculado a esta instituição de ensino. Diante do exposto, o presente trabalho tem como objetivo avaliar a visão e as expectativas dos alunos do Ensino Médio que tem como interesse ingressar em uma instituição de ensino superior seja ela pública ou privada por meio de ingresso o exame nacional do ensino médio.
\end{abstract}

Palavras-Chave: Ensino Superior, Enem, Avaliação.

\section{Introdução}

Interfere-se que há a necessidade de mudanças para uma nova configuração da educação brasileira para torná-la mais utilitária e adequadamente qualificada em uma sociedade cada vez mais globalizada, principalmente ao se considerar a possibilidade de equiparação dela com os demais países desenvolvidos. Para tanto, é inevitável a implementação das diversas políticas educacionais, constituindo mecanismos de sustentação dessa mudança. Várias dessas políticas

\footnotetext{
${ }^{1}$ Licenciatura em Ciências Agrárias, UFPB, e.edvaniapereira@hotmail.com

${ }^{2}$ Licenciatura em Ciências Agrárias, UFPB, Leandroaraujo@hotmail.com

${ }^{3}$ Licenciatura em Ciências Agrárias, UFPB, daivydoliver@hotmail.com

${ }^{4}$ Professora do Departamento de Educação, UFPB, claudia.cavn@yahoo.com.br
} 
educacionais destinam-se a avaliar a qualidade da educação no país. Dentre elas, destaca-se o Exame Nacional do Ensino Médio - Enem.

O Enem, desde sua criação em 1998, vem-se submetendo a reformulações em seus objetivos centrais. Inicialmente utilizado apenas como instrumento de critério de seleção de alunos que almejavam uma bolsa integral ou parcial no Programa Universidade Para Todos - Prouni, destinado aos estudantes de baixa renda que possuem diploma de curso superior, agora também poderá ser usado como critério geral para o ingresso em instituições federais e privadas.

Criado em 1998 pelo Ministério da Educação - MEC, o Enem tem o propósito de avaliar o desempenho do estudante ao fim da escolaridade básica, visando aferir o desenvolvimento das competências e habilidades necessárias ao exercício pleno da cidadania (Andriola, 2011).

Atualmente, a prova do Enem é interdisciplinar e contextualizada, buscando colocar o aluno diante de situações-problema para mensurar não apenas se ele conhece os conceitos, mas se sabe aplicá-los. É tido como um exame que segue uma referência teórica construtivista. Suas provas têm sido elaboradas priorizando a resolução de problemas. (Macedo, 2005).

A preocupação com a qualidade na área educacional sempre esteve presente, no entanto, nunca se falou tanto sobre ela. É indiscutível que a sociedade brasileira está valorizando, cada vez mais, a importância da educação e, percebendo-a como imprescindível para a boa formação de sujeitos competentes. Observa-se também que há um empenho do governo e das políticas públicas para que o ensino se encaminhe para a qualidade e equidade. (Castro, 2007)

O Exame Nacional do Ensino Médio (ENEM) é uma prova aplicada em todo o Brasil com intuito de medir o conhecimento de alunos para o ingresso no Ensino Superior de Universidades públicas e privadas do país. Portanto, se a principal forma de ingresso à universidade é a realização da prova do ENEM, impera que preparemos o aluno do ensino médio para prestar este exame. De acordo com o INEP (Instituto Nacional de Estudos e Pesquisas) a prova do ENEM segue um modelo que o difere dos processos avaliativos tradicionais, uma vez que ela se baseia na interdisciplinaridade e contextualização dos fatos, colocando os estudantes frente a situaçõesproblema e valorizando sua autonomia para fazer escolhas e tomar decisões.

Diante do exposto, o presente trabalho tem como objetivo avaliar a perspectiva dos alunos do ensino médio do Colégio Agrícola Vidal de Negreiros - CAVN da instituição de ensino UPFB Centro de Ciências Humanas, sociais e Agrárias, Campus III - Bananeiras.

\section{Fundamentação Teórica}

O Exame Nacional do Ensino Médio propõe mensurar modalidades estruturais da inteligência, denominadas competências (Brasil, 1998, 2000, 2001). São cinco as modalidades da 
inteligência focadas pelo Enem que, sucintamente, correspondem à capacidade das pessoas em: 1) operar mentalmente diversas linguagens abstratas e fazer uso delas; 2) utilizar e manipular conceitos e procedimentos específicos para compreender os fenômenos; 3) resolver problemas; 4) discutir e analisar estruturas argumentativas; 5) transformar a teoria em propostas e aplicações prático-concretas (Condeixa et al., 2005; Machado, 2005; Macedo et al., 2005; Martino et al., 2005; Menezes et al., 2005; Murrie, 2005).

Para isso, necessitam fornecer as informações necessárias para que os estudantes possam resolver o problema proposto. O desafio é de o aluno ser capaz de interpretar as informações, saber organizá-las, coordená-las adequadamente e projetar possibilidades, envolvendo o tom da novidade, de modo que os esquemas prévios já aprendidos não determinem totalmente a resolução do problema (Fini, 2005).

O Exame Nacional do Ensino Médio (ENEM), criado em 1998 pelo Instituto Nacional de Estudos e Pesquisas Educacionais Anísio Teixeira (Inep), do Ministério da Educação. Ao longo da primeira década do século XXI, foi utilizado como instrumento de certificação de conclusão do Ensino Médio, bem como de critério de acesso ao ensino superior, através de programas como Programa Universidade para Todos (ProUni) e Fundo de Financiamento Estudantil (FIES), além de ter sido aceito como exame de seleção para a maioria das universidades federais do Brasil. $\mathrm{O}$ ENEM é uma avaliação constituída a partir de uma matriz de habilidades e competências que sintetizam os conteúdos ministrados no ensino fundamental e médio. Suas médias, obtidas por escola, podem ser observadas na Internet num ranking de escolas de acordo com as médias obtidas através do cálculo da nota dos candidatos. Sousa (2011) afirma que o ENEM não pode ser considerado um exame que avalia o EM, pois, embora venha sendo difundido como exame para essa etapa do ensino, seus resultados não evidenciam a qualidade do EM cujos objetivos (tanto na sua versão antiga quanto a nova) refletem "[...] o propósito de avaliar individualmente alunos concluintes e egressos do ensino médio quanto às competências especialmente definida para esse exame" (SOUSA, 2011).

\section{Metodologia}

O trabalho foi realizado em maio de 2016 na Universidade Federal da Paraíba (UFPB), Centro de Ciências Humanas Sociais e Agrárias (CCHSA), Campus Universitário III, em Bananeiras - PB. Para a realização desse trabalho, foi discutido uma atividade que envolvesse os alunos do Ensino Médio, para isto, o tema abordando foi o ENEM. Para a coleta de dados deste trabalho foram aplicados questionários fechados. Estes questionários foram destinados para os 
alunos do Colégio Agrícola Vidal de Negreiros que eram regularmente matriculados no terceiro ano do ensino médio.

O questionário conteve questões relacionadas ao ENEM, dentre elas a faixa etária dos participantes, sexo, se eram oriundos de escolas públicas ou privadas, se já teriam participado alguma vez da prova do Enem e o que acharam sobre as questões abrangidas no Exame nacional do ensino médio. F oram indagados se os conteúdos ministrados durante o Ensino Médio eram suficientes ou adequados para se obter resultados satisfatórios no exame. Também foram questionados sobre quais atividades eles realizavam ou realizam como preparação para as provas. Diante dos resultados obtidos partiu-se para análises dos dados coletados, com o intuito de obter um diagnóstico sobre a concepção dos alunos com relação ao Exame Nacional do Ensino Médio ENEM.

\section{Resultados e Discussão}

Dos alunos do colégio agrícola que responderam ao questionário, $44 \%$ eram do sexo feminino e $66 \%$ correspondiam ao sexo masculino. Todos eram regularmente matriculados e não eram repetentes. De acordo com as questões levantadas, 66\% responderam que já tiveram acesso a provas de edições anteriores do exame e $44 \%$ ainda não haviam vivenciado contato algum com as provas. Para os que já teriam contato com a prova, foi proposto que eles fizessem uma avaliação quanto ao tipo de enunciado; $77 \%$ consideraram bom, os demais consideraram regular. Foram questionados também sobre o tempo de duração das provas e sobre as quantidades de questões. Com relação ao tempo disponibilizado para realização das provas 50\% consideraram bom, $25 \%$ regular e $25 \%$ ótimo. Já para a quantidade de questões, $38 \%$ consideraram regular, 37\% disseram que era bom e $25 \%$ afirmaram que a quantidade de questões era ótima.

Os referidos alunos também foram questionados com relação a algumas atividades extraclasse para ajudar no bom desempenho nas provas. $88 \%$ declararam que fazem parte de cursinhos preparatórios para o Enem. Ainda foram questionados se estes alunos recebiam alguma orientação sobre como fazer a inscrição e sobre orientações quanto as provas. $88 \%$ afirmaram ter recebido alguma orientação sobre como realizar a prova e a inscrição. 33\% dos alunos declararam que os conteúdos ministrados no ensino médio são suficientes para a realização de uma boa prova. Os outros $77 \%$ descordaram das afirmativas dos colegas e relatam ser insuficiente para se obter um bom resultado no Enem. (Figura 01) 


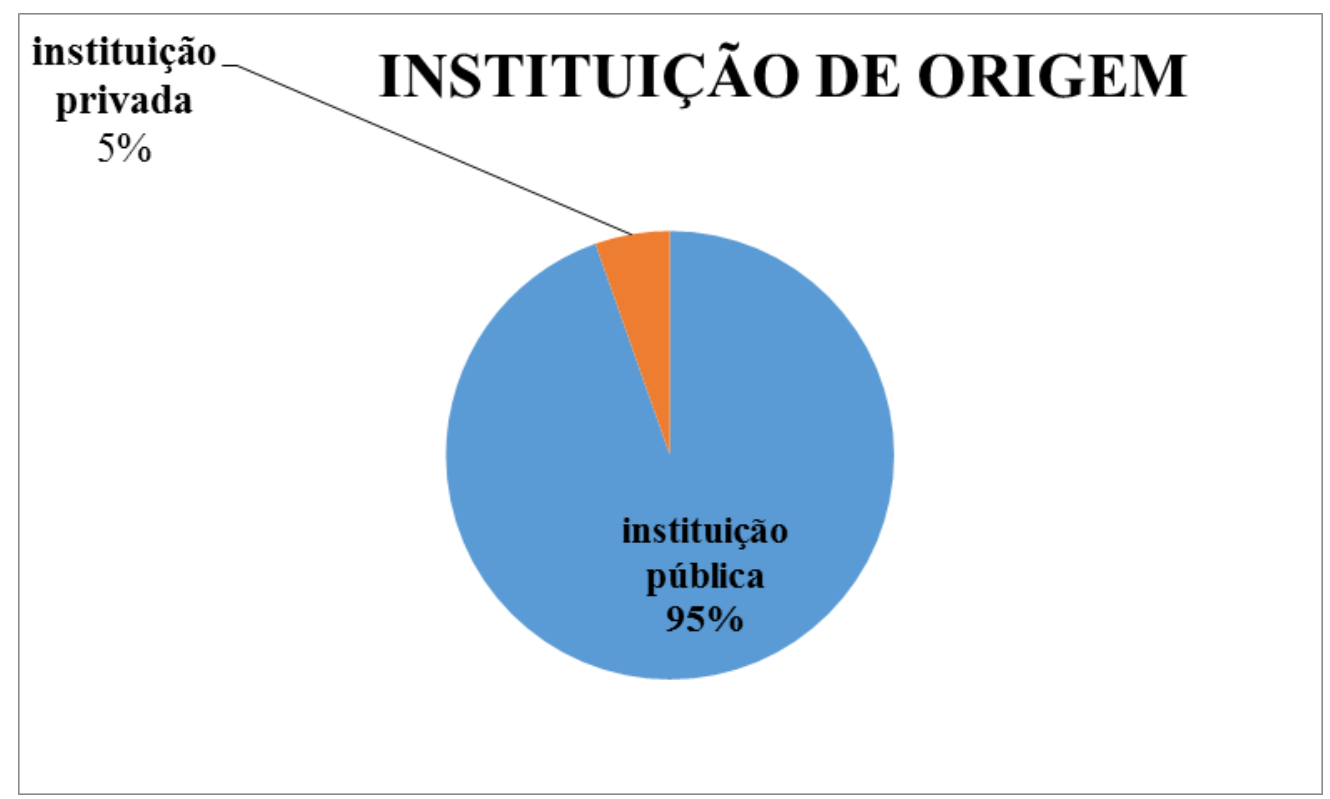

Figura 01. Instituição de origem dos alunos

Os dados mostram que 95\% dos participantes do cursinho preparatório para o Enem vieram de escolas pública e apenas $5 \%$ são oriundos de escolas particulares.

Alunos que participam do cursinho Pró-Enem declararam que 34\% nunca realizaram a prova, sendo que estariam realizando-a pela primeira vez este ano. Os outros $66 \%$ já fizeram outras edições e alguns por mais de uma vez, o que corresponde a $74 \%$ dos alunos. Para os que já tiveram acesso as edições anteriores. Foi proposto que estes realizassem uma avaliação quanto ao tipo de enunciado (figura 02), quantidades de questões (figura 03) e tempo disponibilizado para a realização das mesmas. (figura 04).

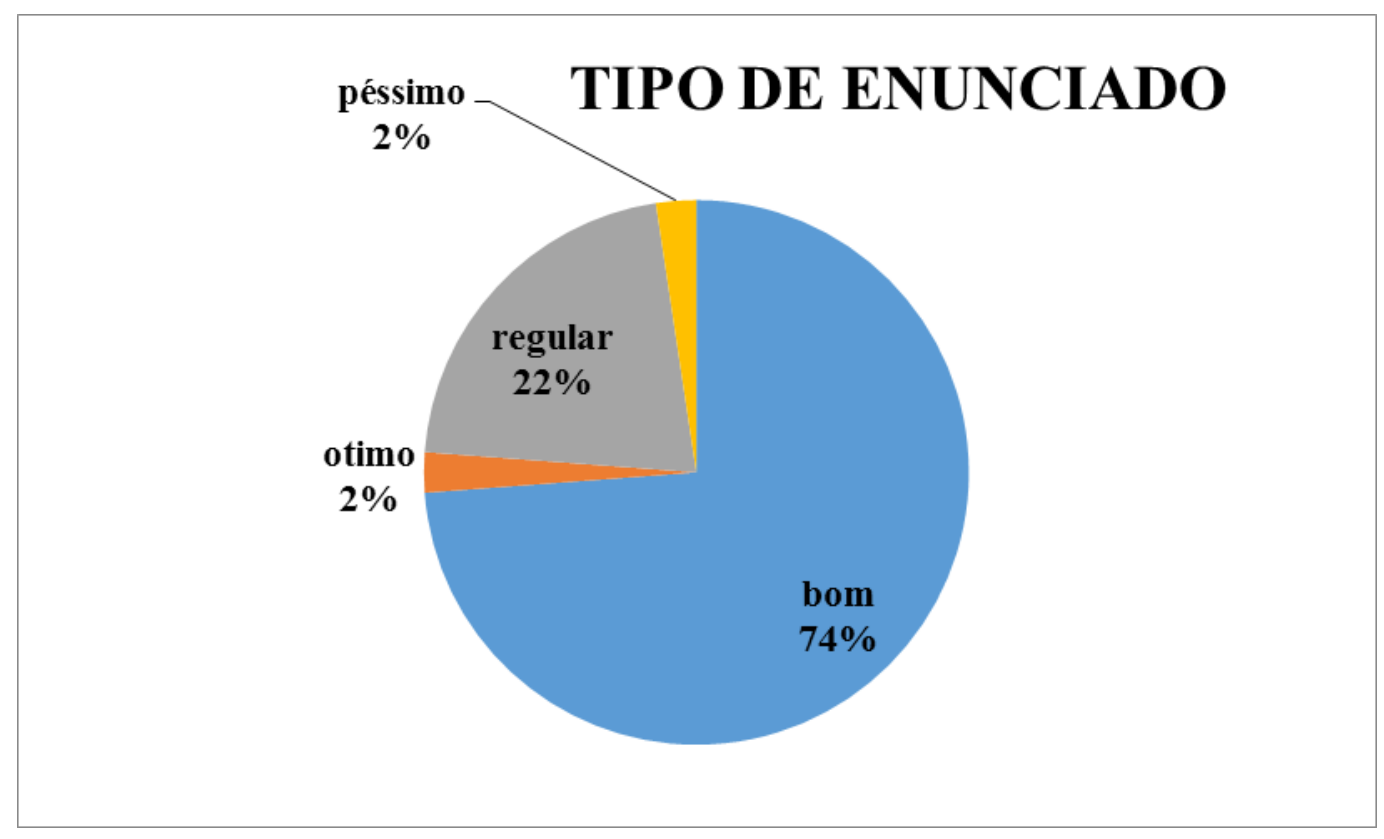

Figura 02. Relação dos alunos quanto ao tipo de enunciado. 


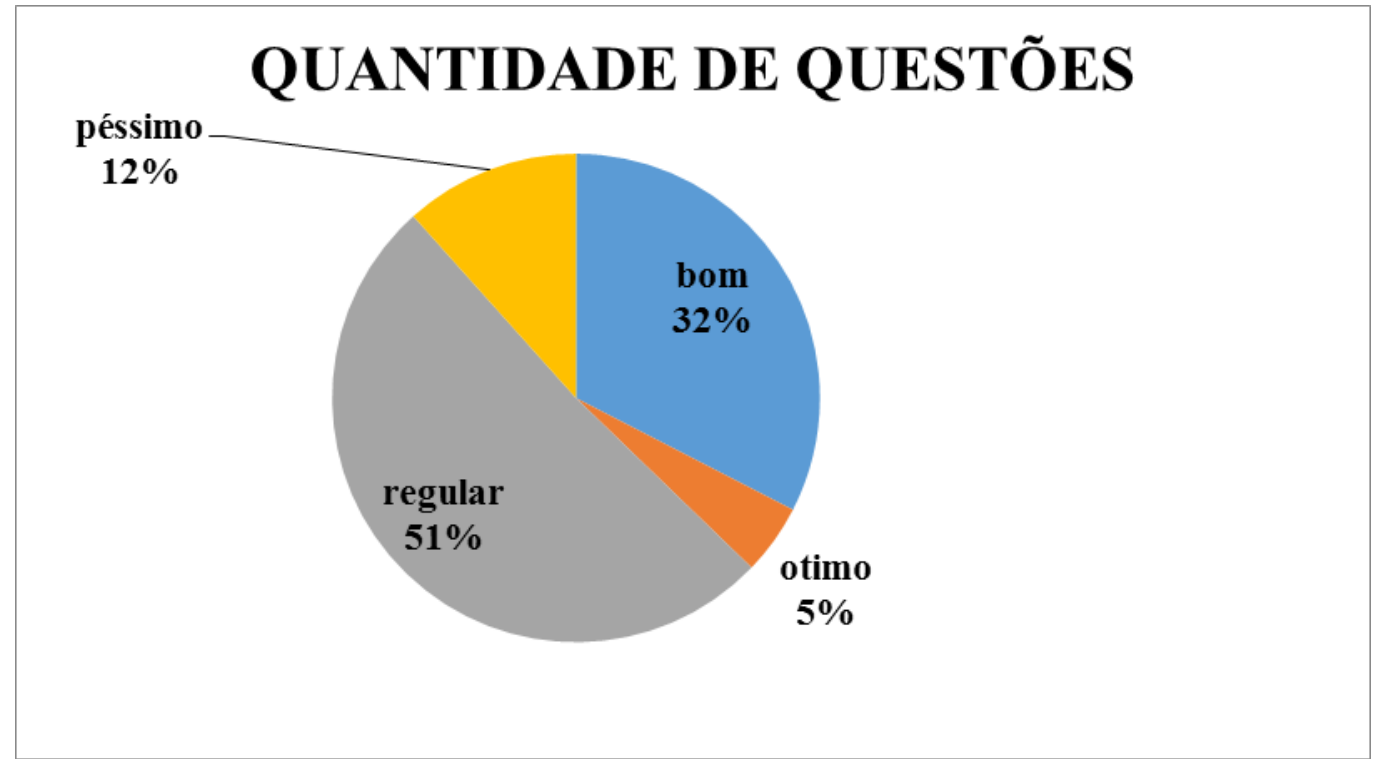

Figura 03. Quantidade das questões disponibilizadas durante a prova.

\section{TEMPO DISPONIBILIZADO}

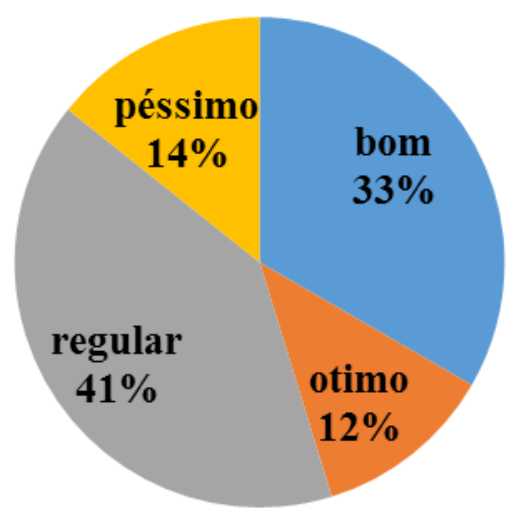

Figura 04. Tempo disponibilizado para a realização da prova. 


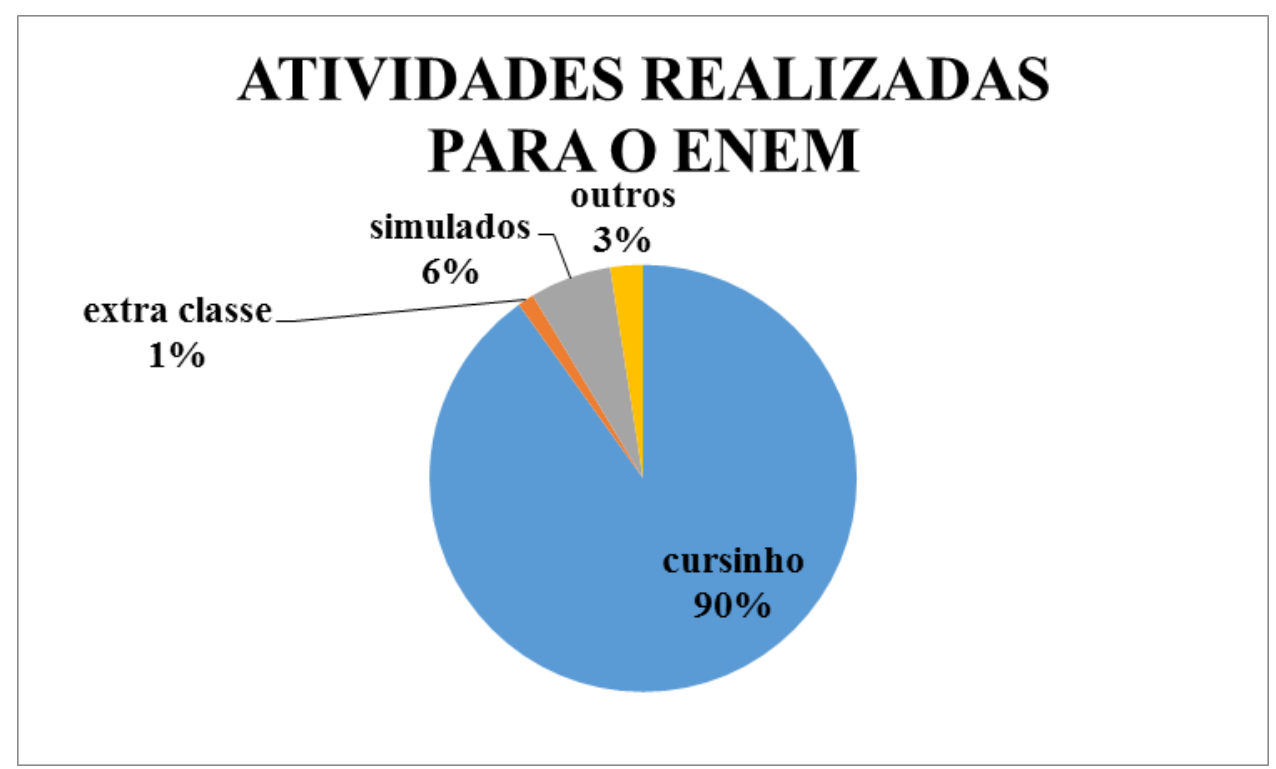

Figura 05. Atividades preparatórias para realização do exame.

90\% dos participantes declararam que tinham como atividade principal de preparação, o cursinho Pró-Enem. $6 \%$ declaram que realizam simulados e apenas $1 \%$ realizam atividade extraclasse, além dos $3 \%$ que realizam outras alternativas.

Com relação aos assuntos abordados no ensino médio, indagamos para os alunos se os mesmos achavam suficientes para obter um bom desempenho nas avaliações. Cujos resultados serão expostos na figura 06.

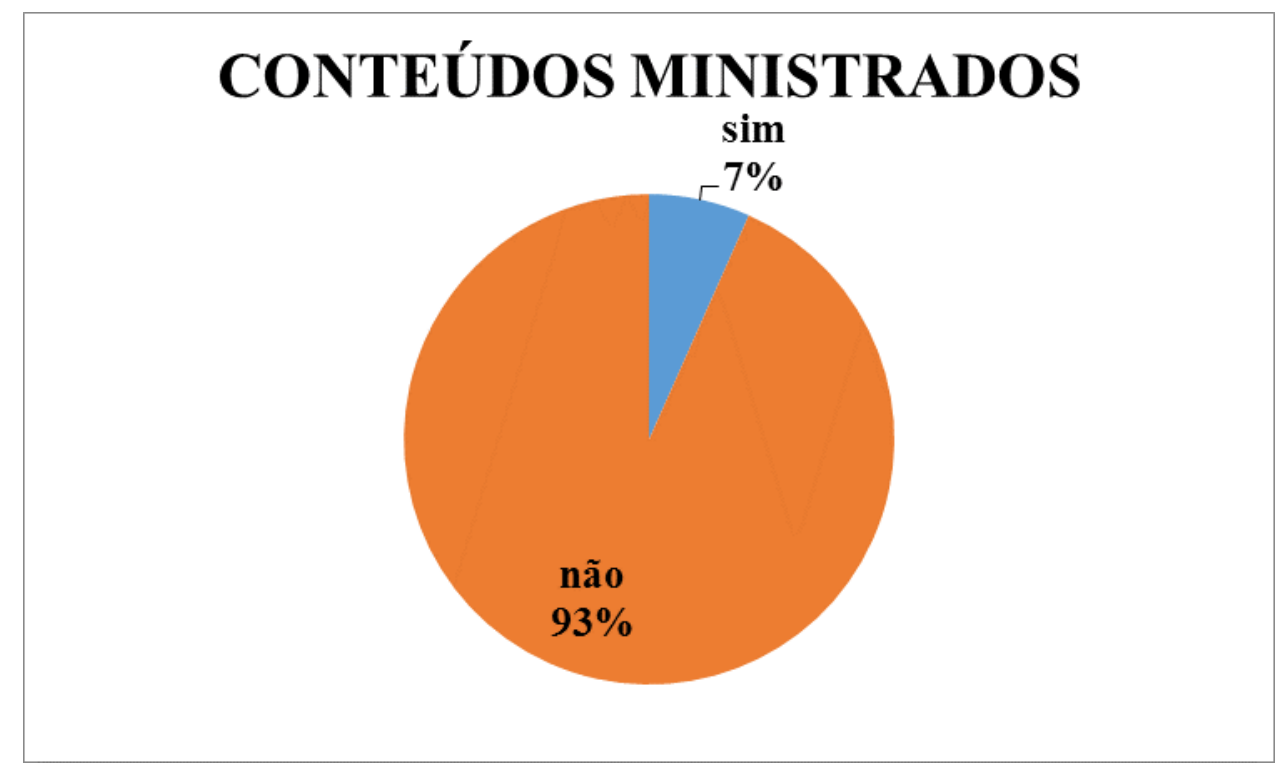

Figura 06. Conteúdos ministrados durante ensino médio.

Grande maioria dos educandos acham que os conteúdos ministrados durante o ensino médio são insuficientes para se obter um resultado significativo, o que faz com que os mesmos procurem 
outros meios para melhorar o seu desempenho e assim, conseguir ingressar em uma instituição de ensino superior, seja ela, pública ou privada.

Quanto a confiabilidade do Enem, para os participantes desta pesquisa, 61\% afirmou ser bom e confiável, outros $15 \%$ consideram excelente, outros $23 \%$ declararam ser ótimo e apenas $1 \%$ afirmaram que este método de avaliação é péssimo.

\section{Conclusões}

De acordo com os resultados obtidos, podemos concluir que os alunos do Colégio Agrícola Vidal de Negreiros - CAVN - UFPB acreditam ser insuficiente os assuntos ministrados durante o Ensino médio para obtenção de um bom resultado no Exame Nacional do Ensino Médio.

Concluímos ainda que o tempo destinado para realização das provas, tipo de enunciado e quantidade de questões são satisfatórios para a realização do mesmo.

Mesmo com a melhoria no sistema educacional do nosso país, ainda é preciso que haja mais qualificação no quadro de docentes das escolas públicas voltados para o Ensino Médio, pois é preciso que estes atendam a uma perspectiva que o Enem exige dos educandos do nosso País.

\section{Referências}

ANDRIOLA, W. B. Doze motivos favoráveis à adoção do Exame Nacional do Ensino Médio (Enem) pelas Instituições Federais de Ensino Superior (Ifes). Ensaio: avaliação e políticas públicas em Educação, 2011.

BRASIL. Ministério da Educação. Parâmetros Curriculares Nacionais: ensino médio. Secretaria de Educação Média e Tecnológica. Brasília: Ministério da Educação. 1999.

BRASIL. Ministério da Educação. Instituto Nacional de Estudos e Pesquisas Educacionais Anísio Teixeira. Exame Nacional do Ensino Médio (Enem): fundamentação teórico-metodológica. Brasília, 2005.

CASTRO, M.H.G. O desafio da qualidade. In: O Brasil tem Jeito? II volume. Jorge Zahar Editor, 2007.

MACEDO, L. de. Competências e habilidades: elementos para uma reflexão pedagógica. In: BRASIL. Ministério da Educação. Instituto Nacional de Estudos e Pesquisas Educacionais 
Anísio Teixeira. Exame Nacional do Ensino Médio (Enem): fundamentação teórico-metodológica. Brasília, 2005.

CONDEIXA, M. C. G. et al. Competência I. In: BRASIL. Ministério da Educação. Instituto Nacional de Estudos e Pesquisas Educacionais Anísio Teixeira. Exame Nacional do Ensino Médio (Enem): fundamentação teórico-metodológica. Brasília, 2005.

FINI, M. E. Erros e acertos na elaboração de itens para a prova do Enem. In: BRASIL. Ministério da Educação. Instituto Nacional de Estudos e Pesquisas Educacionais Anísio Teixeira. Exame Nacional do Ensino Médio (Enem): fundamentação teórico-metodológica. Brasília, 2005.

MACHADO, N. J. Interdisciplinaridade e contextuação. In: BRASIL. Ministério da Educação. Instituto Nacional de Estudos e Pesquisas Educacionais Anísio Teixeira. Exame Nacional do Ensino Médio (Enem): fundamentação teórico-metodológica. Brasília, 2005.

MARTINO, M. C. et al. Competência V. In: BRASIL. Ministério da Educação Instituto Nacional de Estudos e Pesquisas Educacionais Anísio Teixeira. Exame Nacional do Ensino Médio (Enem): fundamentação teórico-metodológica. Brasília, 2005.

MURRIE, Z. de F. A Área de linguagens e códigos e suas tecnologias no Enem. In: BRASIL. Ministério da Educação. Instituto Nacional de Estudos e Pesquisas Educacionais Anísio Teixeira. Exame Nacional do Ensino Médio (Enem): fundamentação teórico-metodológica. Brasília, 2005.

MENEZES, L. C. de et al. Competência II. In: BRASIL. Ministério da Educação. Instituto Nacional de Estudos e Pesquisas Educacionais Anísio Teixeira. Exame Nacional do Ensino Médio (Enem): fundamentação teórico-metodológica. Brasília, 2005 